\title{
Is the birch pollen threat the same indoors and outdoors?
}

\author{
Alina Stacewicz', Małgorzata Puc, 2 \\ ${ }^{1}$ Department of Botany and Nature Conservation, Faculty of Biology, University of Szczecin, Poland \\ ${ }^{2}$ Institute of Marine \& Environmental Sciences, University of Szczecin, Poland
}

\begin{abstract}
:
The study compares the concentration of birch pollen indoors and outdoors in 2019. The investigations were carried out using the volumetric method (Hirst type pollen sampler). Seasonal Pollen Index (SPI) was estimated as the sum of daily average pollen concentrations in the given season. Pollen season was defined as the period in which 98\% of the annual total catch occurred. The birch pollen season in 2019 started at the beginning of April. The first pollen grains were recorded in internal samples on the April $4^{\text {th }}$, only one day after than in external air. In generally the period of occurrence of birch pollen in the outdoor and indoor air coincided (28/29 days). The maximum values of seasonal birch pollen count were noted on April $18^{\text {th }}\left(467 \mathrm{~g} / \mathrm{m}^{3}\right)$ and on April $20^{\text {th }}\left(1971 \mathrm{~g} / \mathrm{m}^{3}\right)$ (indoor/outdoor). The annual pollen sum of birch noted outdoor reached 18148 , inside seminary room - 3141, which is $17 \%$ of total. Three peaks of high concentrations of birch pollen were noted outside, which was only partly reflected in the indoor air. This may be result of closing the windows for the night and on weekends. The threat of birch pollen allergens during the 2019 pollen season was high. For most of the season in outside air were noted values in which patients report severe allergy symptoms. Such concentrations were recorded for 9 days indoor with concentration above $90 \mathrm{grains} / \mathrm{m}^{3}$ (acute symptoms of allergy).
\end{abstract}

Key words: birch (Betula), indoors pollen, aeroallergens, pollen count, 2019

P eople nowadays spend most of their time indoors, it is estimated that it is even $80 \%$ to $95 \%$ [1-3]. The air we breathe, external or internal, contains many biological originated particles that pose a threat to our health. The quality and composition of the air we breathe have a major importance, especially for people suffering from inhalation allergies, including pollinosis. Pollen of anemophilous plants is an important component of air, and because particular plants bloom at different times, they can occur in the air almost all year. Pollen is transferred to the interior, among others, through air ventilation - through open windows or doors, it can be sucked in by artificial ventilation / air conditioning, people are also a vector, bringing pollen on clothes or shoes $[4,5]$.

One of the most important allergenic tree species in Poland and Europe is birch. The major allergens of pollen from trees belonging to the Fagales order have a degree of cross-reactivity because they are structurally and immunochemically similar, although the cross-reactivity appears to be strongest within botanically established families rather than between them. There is also a cross-reactivity observed between birch pollen allergens and food (apple, apricot, cherry, peach, pear, plum and kiwi) [6]. All birches are wind-pollinated and produce large amounts of light pollen, which enables its wide dispersal. In Poland Betula flowers from the second half of April almost to the end of May. Production of pollen in birches is said to follow a two-year cycle. The beginning of pollination is closely related to the air temperature within the period of 40 days prior to the occurrence of pollen in the air [7].

The genus Betula is restricted in its appearance to the cool and temperate zones of Europe and contains mainly the two species of tree birches: Betula pendula Roth., B. pubescens Ehrh. and the two species of shrub birches: B. humilis Schrank, B. nana L. [8]. B. pendula occurs throughout Europe except of Iberia, the Mediterranean lowlands, northern Fennoscandia and the Arctic. B. pubescens avoids only the Mediterranean 
basin. Birches are essentially pioneer trees with a high tolerance of climatic and soil condition. B. pendula is well adapted to continental conditions, tolerates summer high temperatures and very cold winters. Like B. pubescens it is resistant to frost [9].

In London it has been reported that at the beginning of birch pollen season, $90 \%$ of patients with birch pollinosis reported mild symptoms above $80 \mathrm{~g} / \mathrm{m}^{3}$ [6] (in Poland at concentration of $75 \mathrm{~g} / \mathrm{m}^{3}$ - symptoms present in all examined patients [10]). However, during the late season, $80 \%$ patients remain symptomatic at a level below $30 \mathrm{~g} / \mathrm{m}^{3}$ [5] (in Poland at concentration of $20 \mathrm{~g} / \mathrm{m}^{3}$ - first symptoms [10]). Therefore, the assessment of indoor air quality in the birch pollen season is important in preventing excessive exposure to birch pollen allergens in sensitized patients.

Indoor air composition study and reference of this data to routinely performed tests of outdoor air will allow to evaluate the quality indoor air and assess direct risk for people staying indoors, especially during intensive pollination of highly allergenic plants.

\section{Aim}

The aim of the study was to compare the analysis of birch pollen season in 2019 and indication of the risk of pollen allergens indoors and outdoors.

\section{Material and method}

Measurements of bioaerosols were carried out in Szczecin, indoor and outdoor, in 2019. Measurements were performed using the volumetric method. The used devices, which are recommended by the IAA (International Association for Aerobiology), take air samples (Burkard and Lanzoni pollen sampler) in volumes corresponding to average human respiratory parameters. Pollen samplers were placed in the building of the Faculty of Biology: Burkard sampler is located in the seminar room, and Lanzoni sampler - on the roof of the building, at a height of $21 \mathrm{~m}$ above ground level. During the day, a window was opened in the seminar room to investigate the potential exposure of the room's users to pollen allergens, given the normal indoor conditions. The window in the room was closed every evening and opened the following morning. It was also closed during the weekend (during this time pollen concentration clearly decreased).

The duration of the pollen season was determined by the $98 \%$ method [6], assuming that the onset and end of the season were days with recorded $1 \%$ and $99 \%$ of the annual total of pollen grains, respectively. Due to the morphological similarity of the pollen grains of yew and juniper, the pollen seasons of both taxa were considered together. The total pollen count over this period was expressed by the SPI (Seasonal Pollen Index). The features characterizing the birch pollen season were determined separately for samples collected from outdoor air and inside the seminary room.

Based on literature data, the number of days was determined in which concentrations of birch pollen exceed the threshold values of consecutive allergy symptoms' development (tab. 1) [10].

\section{Results and discussion}

During certain meteorological conditions, birch pollen has the potential to be transported over long distances from one region to another. The model calculations of atmospheric transport and measurements of birch pollen have shown that long-distance transport from Poland and Germany affect places such as Denmark before the local trees start to flower [11]. Long-distance transport of birch pollen also influences the values of birch pollen concentration recorded both indoors and outdoors, analysed in this paper.

Pollen season of birch in 2019 started at the beginning of April, first pollen grains were recorded indoors on the April $4^{\text {th }}$, on the next day in outdoor air. The duration of the season outdoors overlapped with indoors. The season ended, in both cases, on May $2^{\text {nd }}$, after 28 and 29 days, for outdoors and indoors respectively. The annual pollen sum of birch noted outdoors reached 18 148, during that time the inside of the semi-

Table 1. Characteristics of birch pollen concentrations of indoors and outdoors in 2019, in Szczecin.

\begin{tabular}{|c|c|c|c|c|c|c|c|c|}
$\begin{array}{c}\text { Features of } \\
\text { pollen season/ } \\
\text { monitoring site }\end{array}$ & $\begin{array}{c}\text { Date of start of } \\
\text { pollen season }\end{array}$ & $\begin{array}{c}\text { Duration of main } \\
\text { pollen season } \\
\text { (number of days) }\end{array}$ & $\begin{array}{c}\text { Seasonal Pollen } \\
\text { Index SPI (total) }\end{array}$ & $\begin{array}{c}\text { Peak value and } \\
\text { peak date }\end{array}$ & $\begin{array}{c}\text { Days } \\
\mathbf{2 0} \mathrm{g} / \mathrm{m}^{3} \\
{[10]^{*}}\end{array}$ & $\begin{array}{c}\text { Days } \\
\mathbf{7 5} \mathrm{g} / \mathrm{m}^{3} \\
{[10]^{* *}}\end{array}$ & $\begin{array}{c}\text { Days } \\
\geq 90 \mathrm{~g} / \mathrm{m}^{3} \\
{[10]^{* * *}}\end{array}$ & $\begin{array}{c}\text { Days } \\
\geq 155 \mathrm{~g} / \mathrm{m}^{3} \\
{[10]^{* * * *}}\end{array}$ \\
\hline Indoors & April 4th & 29 & 3141 & $467-18 \mathrm{IV}$ & 14 & 9 & 9 & 7 \\
\hline Outdoors & April $5^{\text {th }}$ & 28 & 18148 & $1971-20 \mathrm{IV}$ & 27 & 26 & $25 \nmid$ & 21 \\
\hline
\end{tabular}

* first clinical symptoms of allergy; ** symptoms present in most patients; *** acute symptoms; **** dyspnea symptoms. 
nary room registered 3141 pollen grains, which is $17 \%$ of total outdoor pollen. There are differences in dates of the highest birch pollen values. The maximum value of seasonal birch pollen count in seminary room was noted on April $18^{\text {th }}\left(467 \mathrm{~g} / \mathrm{m}^{3}\right)$ and on April $20^{\text {th }}(1971$ $\mathrm{g} / \mathrm{m}^{3}$ ) in outdoor air. It might correspond with periods when the window was closed (among others precisely on Saturday April $20^{\text {th }}$ ).

For 27 out of 28 days, which is $96 \%$ of the total length of the season, concentration in outdoor air exceeded the threshold $20 \mathrm{~g} / \mathrm{m}^{3}$. Internal birch pollen concentrations at the same level were noted for about $50 \%$ (of the duration) of the season. Number of days with concentrations exceeding threshold $90 \mathrm{~g} / \mathrm{m}^{3}$ in external samples was 26 days - $93 \%$ of the total length, in indoor air there were 9 days $-31 \%$.

Birch pollen concentration in indoor air, even during the intensive pollination period, reached clearly lower values than recorded at the same time outside. However, during 7 out of 29 days were recorded average daily concentrations higher than $155 \mathrm{~g} / \mathrm{m}^{3}$ were recorded, for which dyspnoea symptoms may occur. Therefore, through $1 / 4$ of the season indoor were noted concentrations significantly threatening to people allergic to birch pollen. There were no birch pollen grains in internal air or we noted very low concentrations during the time when windows were closed (fig. 1 - weekends are marked with squares) during the night and on every weekend, from Friday 9 p.m., till Monday 8 a.m. Lack or low values of pollen was observed even though there were high or very high outside concentrations, including the maximum values of seasonal pollen count $\left(1971 \mathrm{~g} / \mathrm{m}^{3}\right)$ noted in outdoor air.

Research conducted in Finland by Hugg and Rantio-Lehtimäki also confirms much lower internal concentrations in comparison to external ones. It shows that concentrations of Betula pollen decreased substantially toward from outdoors to indoors, and further toward the centre of the building, probably indicating relatively poor penetrating properties of the pollen grains and/or the short-lived presence of pollen grains in indoor air [12]. During this study they registered indoor concentrations lower than $10 \mathrm{~g} / \mathrm{m}^{3}$ further from the main front door at all study sites. On the other hand, studies carried out in Szczecin have shown that exposure to birch pollen allergens indoors is up to 40 times higher than in Finland [12].

Menzel and others [1] observed lower indoor concentrations, at the same time emphasized that the indoor/outdoor ratio was highest in a room with fully opened window and additional mechanical ventilation, followed by rooms with fully opened windows and the lowest in neighboring rooms with tilted window. They concluded that indoor concentrations additionally depended on the previously noted concentrations (high outdoors pollen count), indicating accumulation of pollen inside the rooms even after the full flowering period.

Bastl and others [5], attempted to answer the question whether there is an advantage of staying in a room for people suffering from pollen allergy. The more so because the air in the room has a strong connection with the outside air. The authors concluded that allergy sufferers are exposed indoors to a similar and richer spectrum indoors to that outdoors, but in a much lower quantity. Our study also shows that patients with birch pollen allergy staying indoors were exposed to considerably lower pollen concentrations. However, these values were still potentially risky for allergy sufferers. Closing windows during the day or very brief

Figure 1. Comparison of indoors and outdoors of birch pollen count.

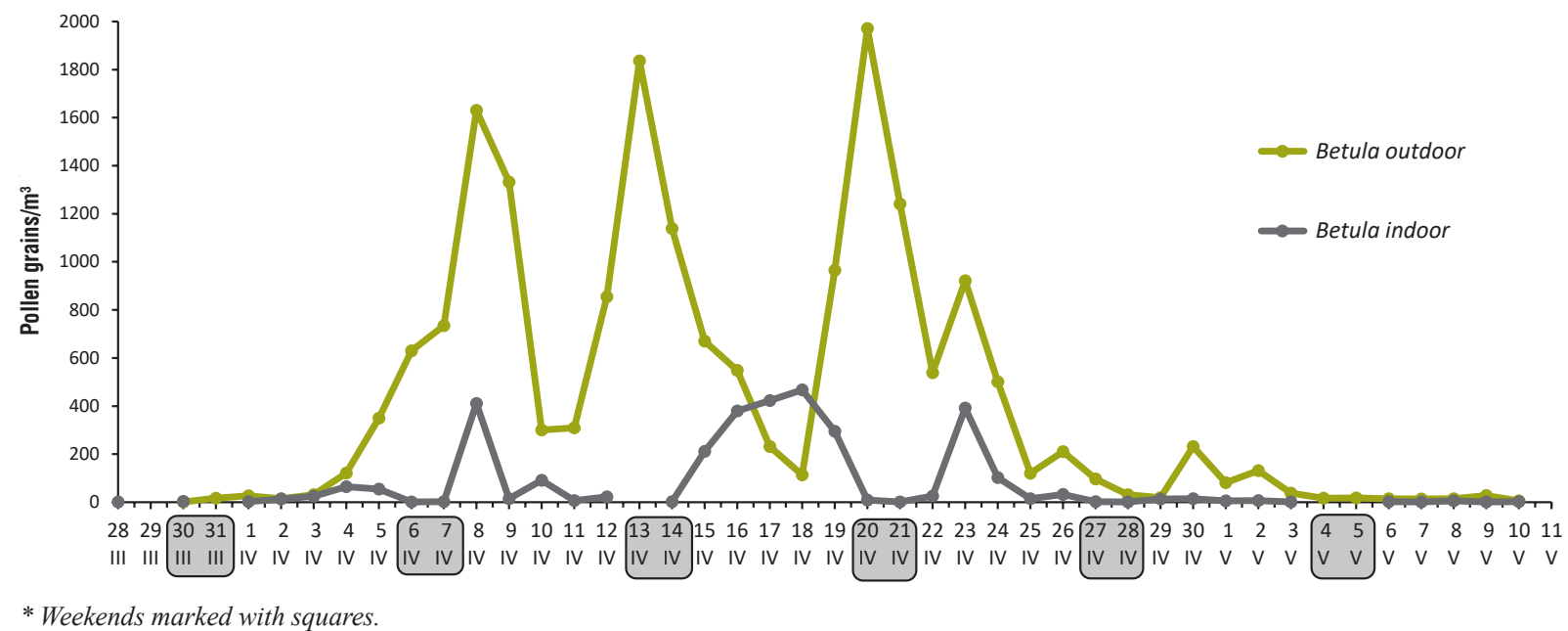


ventilation of the rooms will significantly reduce the risk of pollen allergy.

\section{Conclusions}

Composition and concentration of pollen in the indoor air are the reflection of aerobiological situation on the outside/outdoor condition.

In Szczecin the period of occurrence of birch pollen in the outdoor and indoor air coincided.

In 2019 the threat of birch pollen both in the indoor and in the outdoor air was high.

The annual pollen sum of birch noted inside seminary room comprised $17 \%$ of total annual pollen sum noted outdoors (during the pollen season the windows in the room were closed on weekends).

The pollen of plants penetrates into the rooms, especially when the windows are opened, while closing windows can significantly reduce the level of indoor allergens.

\section{References}

1. Menzel A, Matiu M, Michaelis R, Jochner S. Indoor birch pollen concentrations differ with ventilation scheme, room location, and meteorological factors. Indoor Air 2017, 27(3): 539-550.

2. Höppe P, Martinac I. Indoor climate and air quality. Review of current and future topics in the field of ISB study group 10. Int J Biometeorol 1998, 42: 1-7.

3. Sterling DA, Lewis RD. Pollen and fungal spores indoor and outdoor of mobile homes. Ann Allergy Asthma Immunol 1998, 80: 279-285.

4. BastlK, Berger U, Kmenta M. Ten questions about pollen and symptom load and the need for indoor measurements in built environment. Build Environ 2016, 98: 200-208.

5. Bastl K, Berger U, Kmenta M, Weber M. Is there an advantage to staying indoors for pollen allergy sufferers? Compo- sition and quantitative aspects of the indoor pollen spectrum. Build Environ 2017, 123: 78-87.

6. Emberlin J, Savage M, Woodman R. Annual variations in the concentrations of Betula pollen in the London area, 1961-1990. Grana 1993, 32: 359-363.

7. Spieksma FTM, Emberlin JC, Hjelmroos $M$ et al. Atmospheric birch (Betula) pollen in Europe. Grana 1995, 34: 51-57.

8. Tutin TG, Heywood VH, Burges NA (eds). Flora Europaea 2. Cambridge University Press, Cambridge 1968.

9. Ralska-Jasiewiczowa $M$, Latałowa $M$, Wasylikowa $K$ et al (eds). Late Glacial and Holocene history of vegetation in Poland based on isopollen maps. Polish Academy of Sciences, Cracow 2004.

10. Rapiejko P, Stankiewicz W, Szczygielski K et al. Progowe stężenia pytku roślin niezbędne do wywołania objawów alergicznych. Otolaryngol Pol 2007, 61(4): 591-594.

11. Skjoth CA, Sommer J, Stach A et al. The long range transport of birch (Betula) pollen from Poland and Germany causes significant pre-season concentrations in Denmark. Clin Exp Allergy 2007, 37: 1204-1212.

12. Hugg T, Rantio-Lehtimäki A. Indoor and outdoor pollen concentrations in private and public spaces during the Betula pollen season. Aerobiologia 2007, 23(2): 119-129.

ORCID

M. Puc - ID - orcid. org/0000-0001-6734-9352

A. Stacewicz - ID - orcid.org/0000-0002-3432-8536

Authors' contributions:

Stacewicz A: $70 \%$; Puc M: $30 \%$.

Conflict of interests: The authors declare that they have no competing interests. Financial support: Does not occur.

Ethics: The contents presented in this paper are compatible with the rules the Declaration of Helsinki, EU directives and standardized requirements for medical journals.

\section{Corresponding author:}

\section{Malgorzata Puc, MD, PhD}

Institute of Marine \& Environmental Sciences, University of Szczecin 71-412 Szczecin, Zygmunta Felczaka 3c e-mail: malgorzata.puc@usz.edu.pl 